\title{
Differential Emotional Experience Leads to Pruning of Dendritic Spines in the Forebrain of Domestic Chicks
}

\author{
Jörg Bock ${ }^{\dagger}$ and Katharina Braun \\ Leibniz Institute for Neurobiology, Project Group Juvenile Learning, \\ Brenneckestr.6, 39118 Magdeburg, Germany
}

\section{SUMMARY}

Auditory filial imprinting induces quantitative changes of synaptic density in the forebrain area mediorostral neostriatum/hyperstriatum ventrale of the domestic chick. The aim of the present study was to examine the time window and the extent and quality of experience that is required for the induction of these synaptic changes. We found that a brief (30 min) experience with the imprinting situation (tone stimulus + mother surrogate) is sufficient to induce spine elimination, which is detectable on postnatal day 7 , but not $80 \mathrm{~min}$ after the presentation of the imprinting stimuli. This synaptic reorganization requires the association of the acoustic imprinting tone with an emotional reward (mother surrogate); acoustic stimulation alone does not lead to detectable synaptic changes. The results of the present study provide further evidence that juvenile emotional learning events, such as filial imprinting, lead to a selective synaptic reorganization.

\section{KEY WORDS}

juvenile learning, functional maturation, social separation, synaptic plasticity

\section{INTRODUCTION}

Early postnatal, emotionally modulated learning events are fundamental for the normal development of socio-emotional competence and intellectual capabilities. Studies in monkeys and humans have shown that the disturbance of such learning processes, induced, for instance, by social or emotional deprivation, leads to severe mental retardation and deficits in psychosocial behavior (Spitz, 1945; Harlow \& Harlow, 1962; Skeels, 1966). We propose that, similar to the experience-dependent developmental reorganization of sensory systems (Goodman \& Shatz, 1993), juvenile emotionally modulated learning events are a prerequisite for the functional development of emotional circuits and learning pathways in the brain.

During early and late childhood, an initial synaptic proliferation followed by a substantial synaptic elimination was described in different cortical areas of the human brain (Huttenlocher, 1979) and also in non-human primates (Zecevic et al., 1989; Bourgeois \& Rakic, 1993; Wolff \& Missler, 1993). These phases of proliferation and elimination of neuronal connectivities, which serve to establish and maintain synaptic networks and functional pathways, may be guided by emotional experience and learning.

We investigate this hypothesis in a welldescribed juvenile learning process, filial imprinting in the domestic chick, which is characterized by the restriction to a sensitive phase, the velocity, and the stability of the learning result (Lorenz, 1935; Bateson, 1966; Hess, 1973). Guinea chicks and domestic chicks easily imprint on rhythmic tone pulses in the presence of a mother surrogate and subsequently develop a strong preference for the imprinting tone (Maier \& Scheich, 1983; 
Wallhäußer \& Scheich, 1987; Bock et al., 1996, 1997). During and after filial imprinting the forebrain area mediorostral neostriatum/hyperstriatum ventrale ( $\mathrm{MNH}$, see Fig. 1), a presumptive equivalent of the mammalian prefrontal cortex and part of recently described imprinting pathway (Metzger et al., 1996, 1998), shows dramatic synaptic reorganization, which includes the pruning of dendritic spines on a distinct neuronal subpopulation, the type I neurons (Wallhäußer \& Scheich, 1987; Scheich, 1987; Scheich et al., 1991). These morphological changes are accompanied by an enhanced stimulus-evoked metabolic and electrical excitability (Wallhäußer \& Scheich, 1987; Bock et al., 1996; Bredenkötter \& Braun, 1997), as well as an enhanced release of glutamate and a decrease of the dopaminergic metabolite homovanillic acid (HVA) (Gruß \& Braun, 1996; 1997).
As these experiments were all conducted in chicks that had performed a series of behavioral training and test sessions, and thereby had acquired multiple experience with the imprinting stimulus, (a) at what time during the learning process the spine pruning is triggered and (b) what degree of experience is required for these synaptic changes to occur was unclear. We addressed these questions in a series of experiments, in which we analyzed the spine frequencies of type I neurons in the $\mathrm{MNH}$ of 7-day-old chicks having different amounts of experience with the imprinting situation and the subsequent behavioral tests (Experiment I).

Furthermore, we tested whether an acoustic stimulation alone (without contact with the emotional stimulus represented by the mother surrogate) is sufficient to induce synaptic reorganization or whether the association between the sensory (acoustic) and the emotional component is

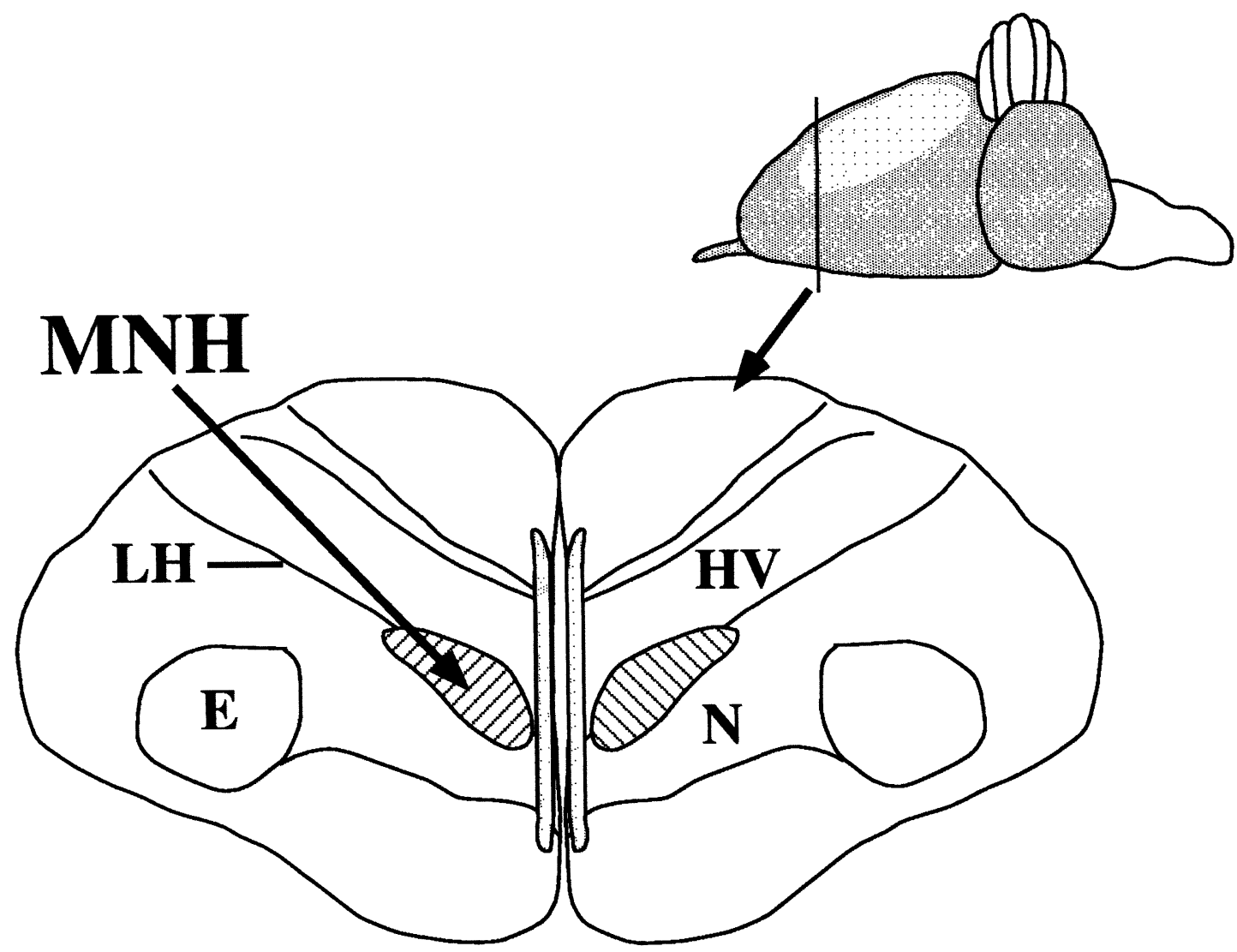

Fig. 1: Location of the imprinting relevant mediorostral neostriatum/hyperstriatum ventrale $(M N H)$ in the chick forebrain. $E=$ ectostriatum, $\mathrm{HV}=$ hyperstriatum ventrale, $\mathrm{LH}=$ lamina hyperstriatica, $\mathrm{N}=$ neostriatum. 
required (Experiment II).

Because in another juvenile learning paradigm, rapid changes (within minutes or hours) in the numerical density of spine synapses have been described in chicks (Doubell \& Stewart, 1993; Stewart \& Rusakov, 1995), we conducted a third experiment, in which we quantified spine densities $80 \mathrm{~min}$ after a brief $(30 \mathrm{~min})$ experience with the imprinting situation (tone pulse + mother surrogate) (Experiment III).

\section{EXPERIMENTAL}

\section{Subjects}

Eggs of White Leghorn chickens, obtained from a local hatchery (Horstmann, Nienburg, Germany), were individually incubated at $37.5 \pm 0.3^{\circ} \mathrm{C}$ in acoustically isolated boxes. After hatching, the chicks were individually reared in these isolation boxes at $28^{\circ} \mathrm{C}$ to $30^{\circ} \mathrm{C}$, with free access to food and water. The boxes were illuminated by diffuse light (light/dark cycle $12 \mathrm{~h} / 12 \mathrm{~h}$ ), and the animals were kept under a continuous white noise level to avoid acoustic deprivation. Such well-controlled rearing conditions were chosen to exclude external sensory stimuli that could lead to incidental imprinting.

\section{Behavioral procedures}

The imprinting procedure and the stimuli used here are described in detail in previous studies (Bock et al. 1996; 1997). In brief, the procedure is as follows: All behavioral training and test procedures were conducted in a V-shaped arena. On the hatching day (day 0 ), the chicks were stimulated for $2 \times 15$ min with a rhythmic tone pulse [frequency modulated with an average frequency of $400 \mathrm{~Hz}$, for details see Bredenkötter \& Braun (1997)] in the presence of a mother surrogate. On day 1 post-hatch, the chicks were submitted to an approach test consisting of two trials. To test whether imprinting had been successful, the chicks had to perform two discrimination tests (on days 1 and 2 post-hatch), consisting of four trials each, in which they were given the choice between the imprinted tone pulse and a novel acoustic stimulus (frequency-modulated tone pulse with an average frequency of $700 \mathrm{~Hz}$ ). During the tests, the mother surrogate was not visible, and the two acoustic stimuli were played alternately from opposite wings of the arena. A discrimination trial was scored positive when the chick approached the imprinting stimulus within $3 \mathrm{~min}$, longer approach times or approaching the unfamiliar tone were scored negative. A complete discrimination test was scored positive if at least three of the four discrimination trials were scored positive, and a chick was considered imprinted only if the two discrimination tests were scored positive.

\section{Experimental groups (Fig. 2)}

Experiment I: This study included four experimental groups, each with a different stimulus experience. All chicks were sacrificed on postnatal day 7 , and the brains were impregnated with a modified Golgi-Cox technique (Glaser \& Van der Loos, 1981).

Naive chicks $(\mathrm{n}=6)$ : These chicks were reared in isolation boxes without any sensory or social contact.

I-tone chicks $(\mathrm{n}=3)$ : On the hatching day (day 0 ), the chicks were stimulated for $2 \times 15 \mathrm{~min}$ with the imprinting tone in the presence of a mother surrogate (hen decoy).

I/A-chicks $(\mathrm{n}=3)$ : The animals were stimulated on day 0 for $2 \times 15$ min with the imprinting stimulus in the presence of a mother surrogate and then were submitted to two approach trials on day 1.

Imprinted chicks $(\mathrm{n}=3)$ : The chicks in this group were exposed on day 0 to the imprinting situation (tone stimulus + mother surrogate) and then tested in two approach trials on day 1 and an overall of 8 discrimination trials on day 1 and day 2 . All chicks of this group showed a clear preference for the imprinting stimulus in the discrimination tests.

Experiment II: All chicks in this experiment were sacrificed on postnatal day 7 .

Naive chicks $(\mathrm{n}=3)$ : The chicks in this group were reared in the isolation boxes without any sensory or social contact. 


\section{Experiment I}

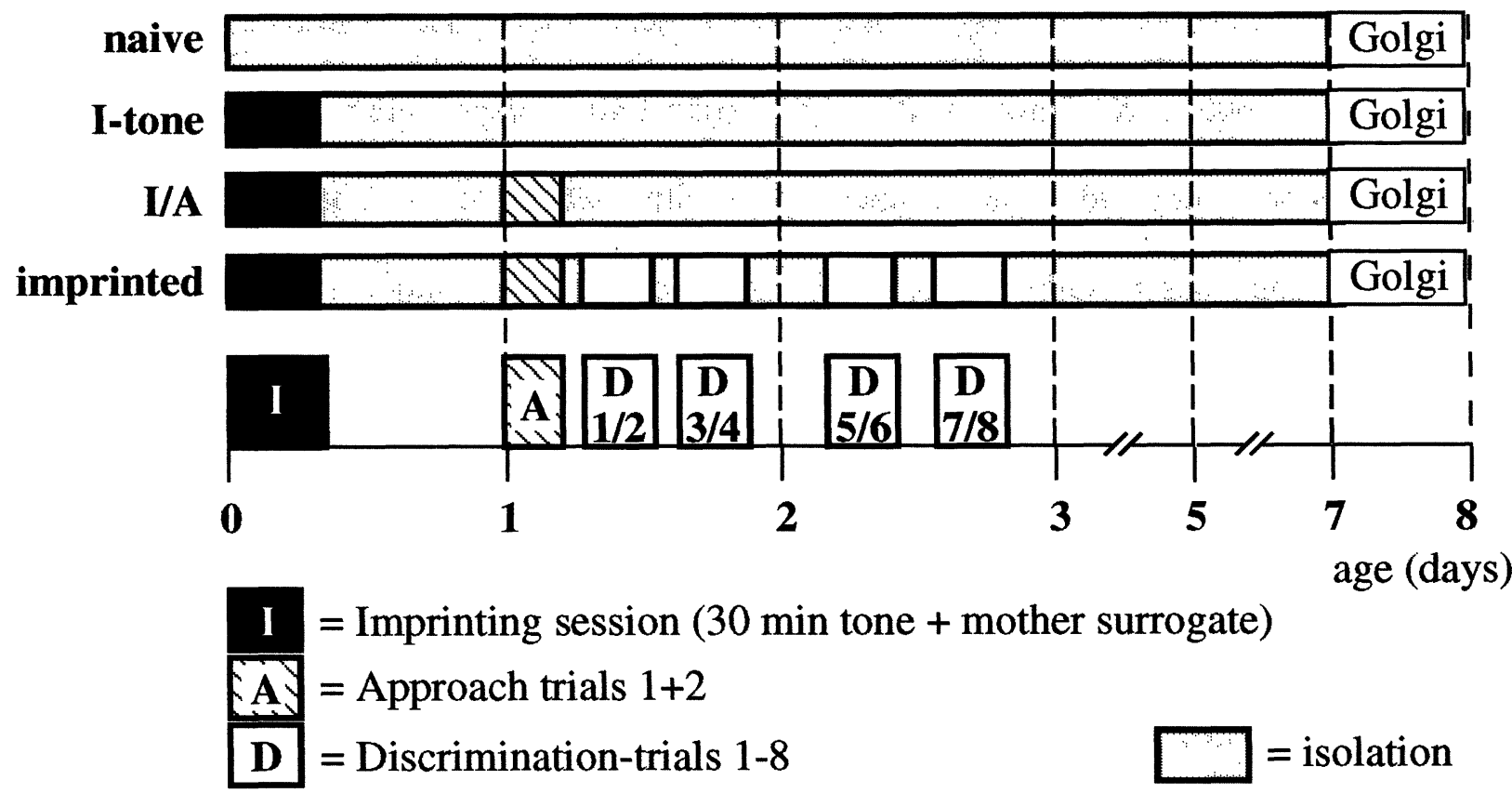

\section{Experiment II}

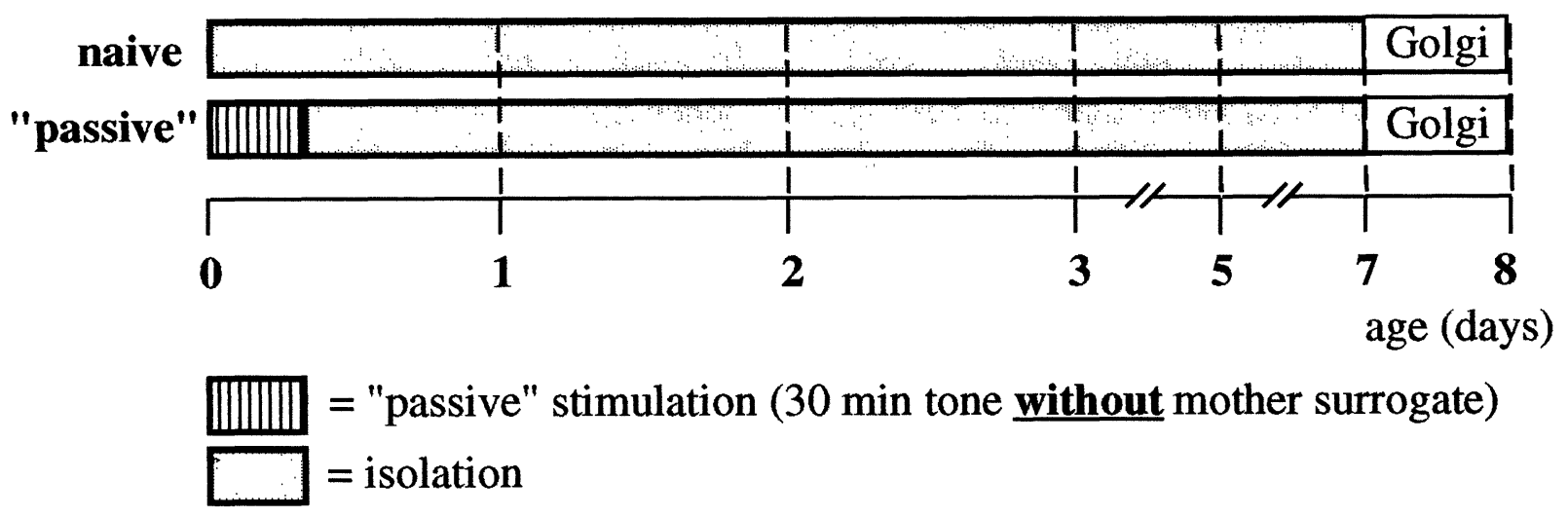

\section{Experiment III}

naive

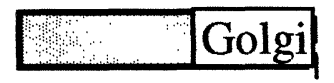

I-tone, do

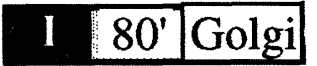

I = imprinting session (30 min tone + mother surrogate)

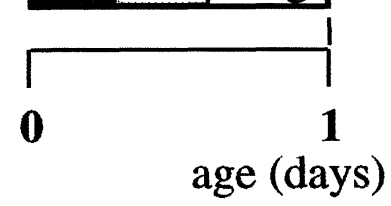

Fig. 2: Experimental design. The bars represent the behavioral treatment of the different experimental groups. See text for further details. 


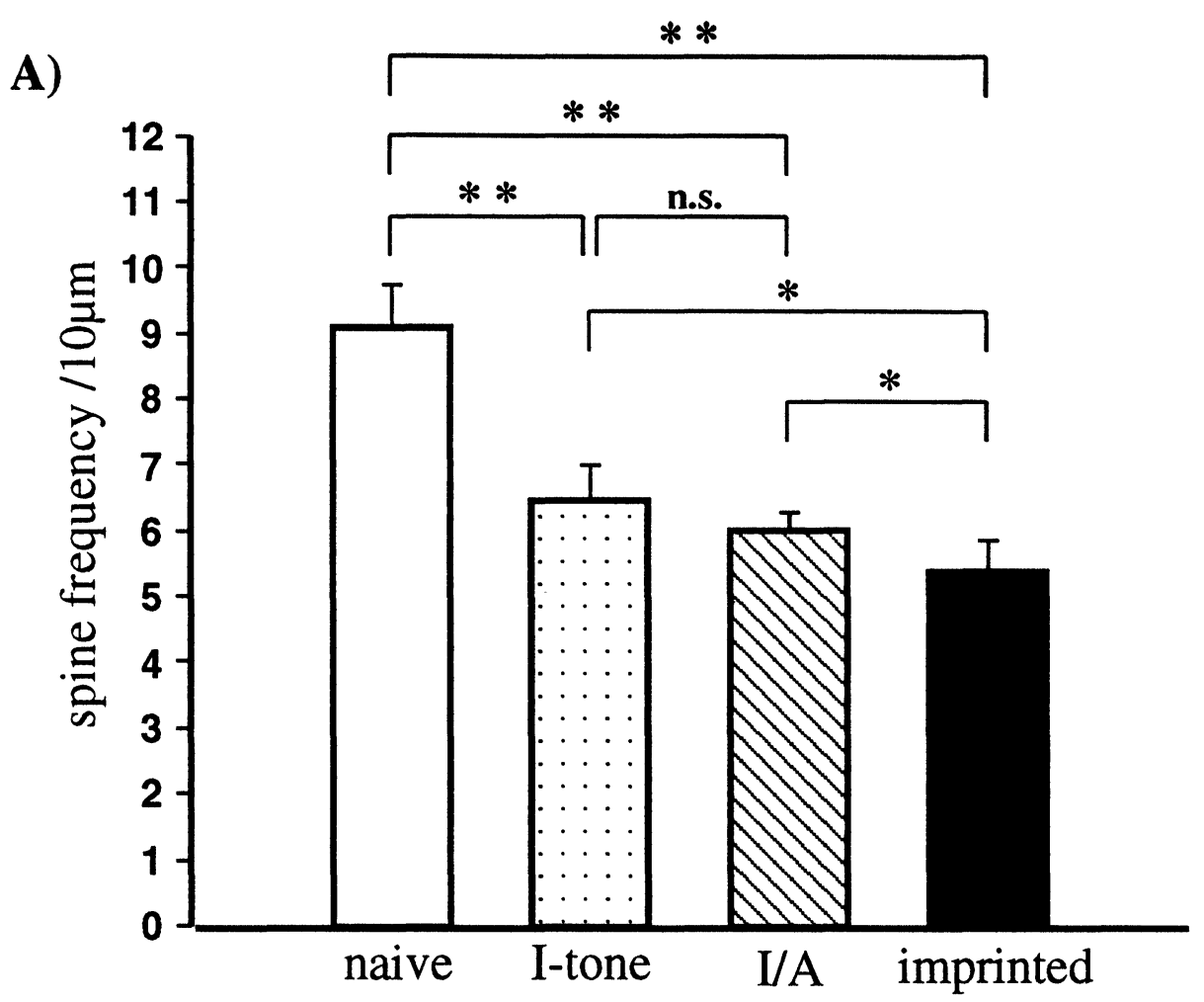

B)

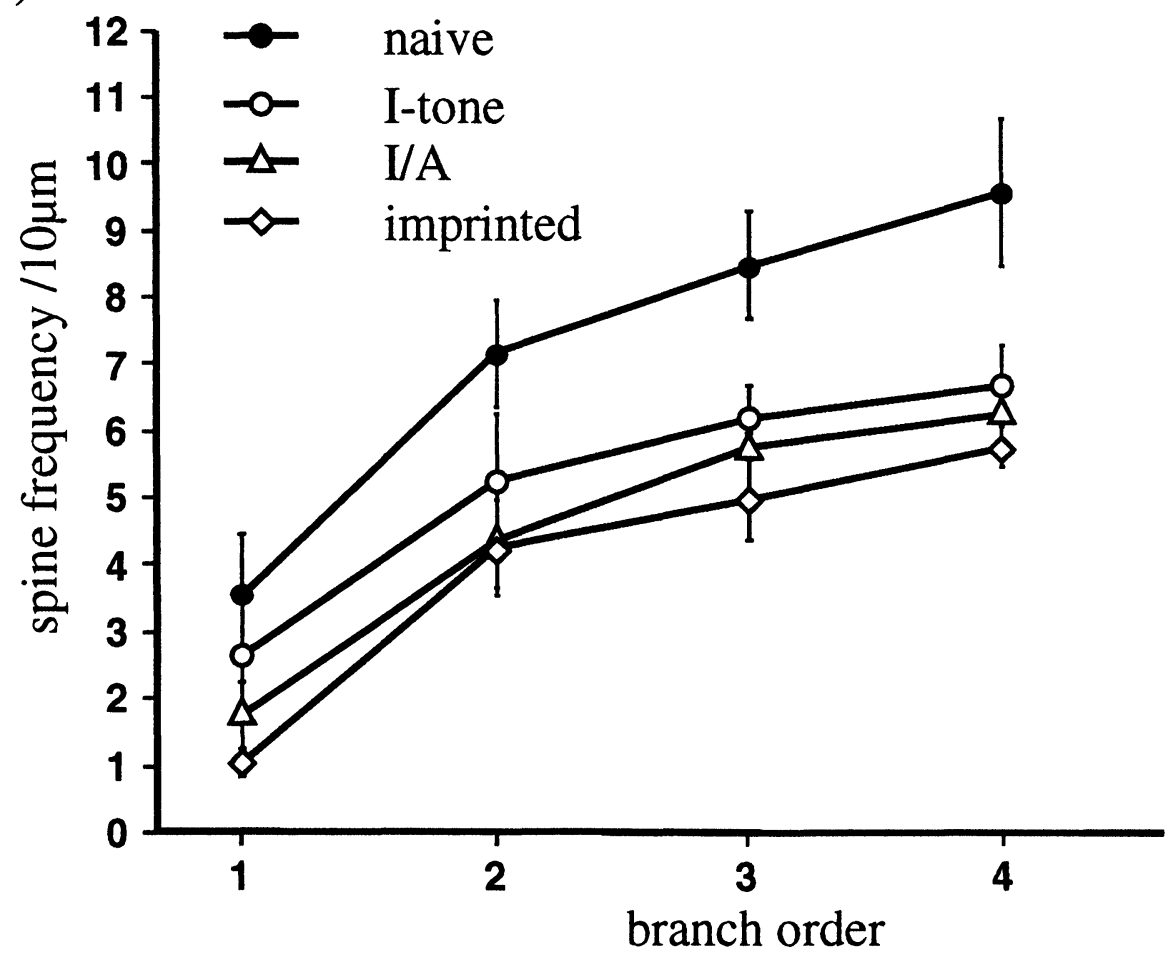

Fig. 3: Spine frequencies from chicks with different behavioral experience (experiment I). Shown are the average spine frequencies and STD of type I neurons in the MNH on postnatal day 7. (A) Average spine frequencies of the 3. and 4. dendritic segments. ${ }^{*} p<0.05 ;{ }^{*} p<0.01$. (B) Average spine frequencies of all dendritic segments from basal (1.) to distal (4.). 


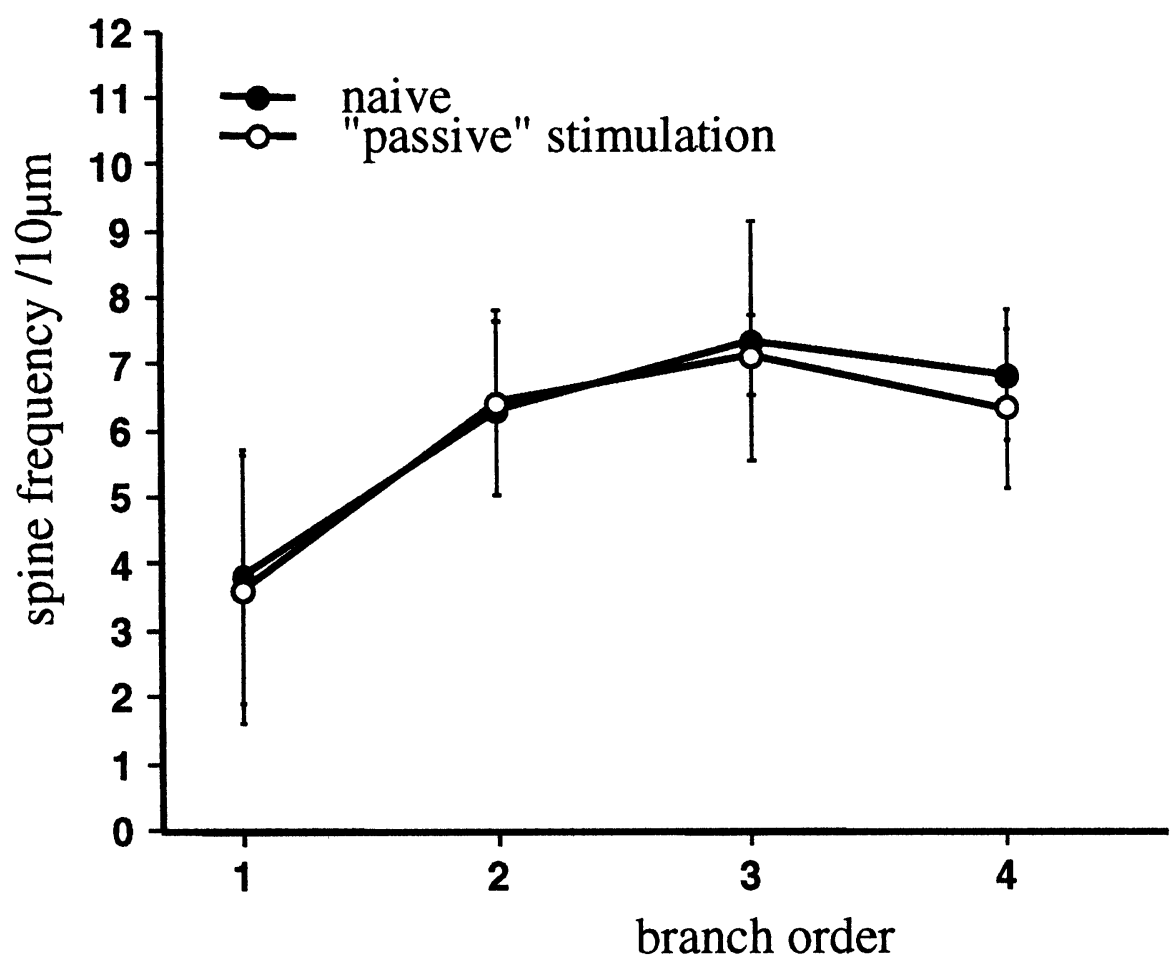

Fig. 4: Spine frequencies after "passive" acoustic stimulation (experiment II). Shown are the average spine frequencies and STD for all dendritic segments of type I neurons in the MNH on postnatal day 7.

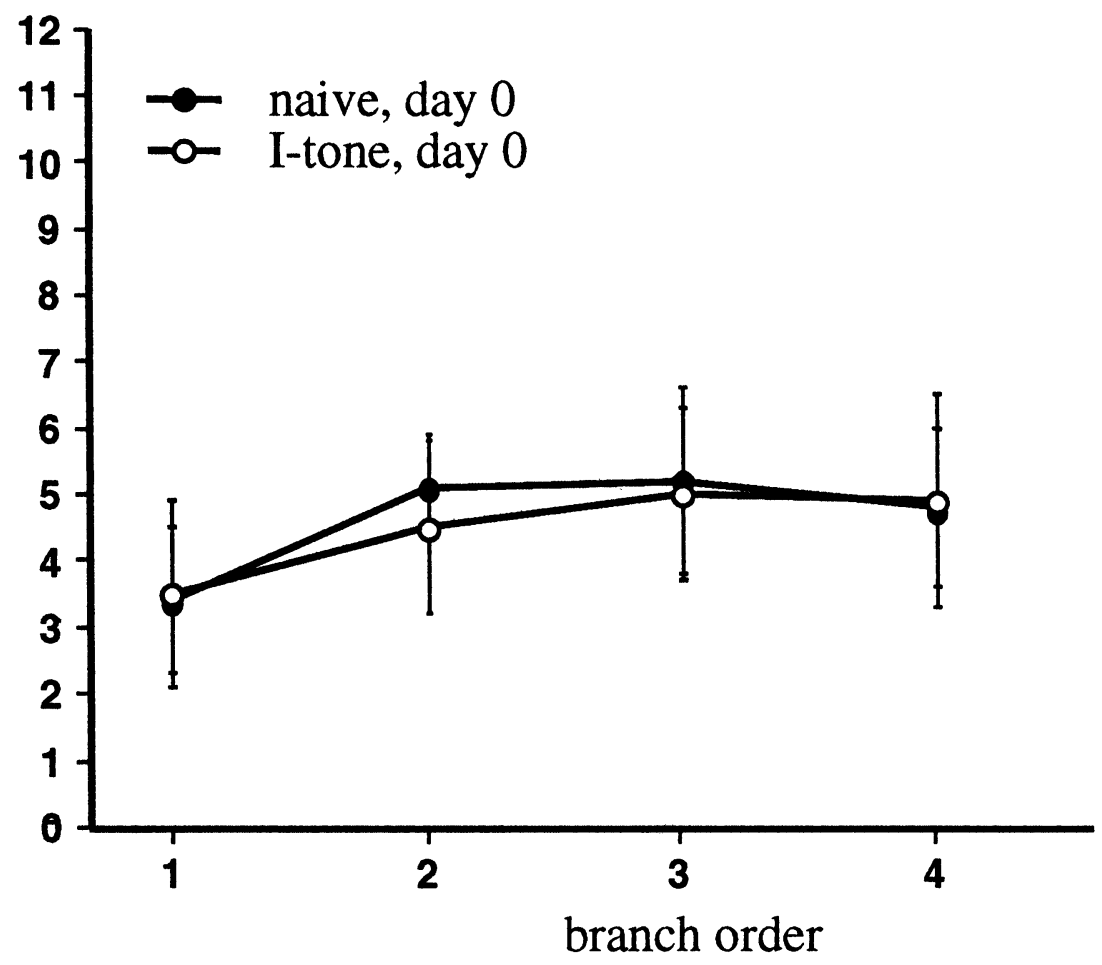

Fig. 5: Spine frequencies on day 0 (experiment III). Shown are the average spine frequencies and STD of type I neurons for all dendritic segments of type I neurons in the $\mathrm{MNH}$ on the hatching day (day 0 ). 
"Passive" stimulation $(\mathrm{n}=3)$ : On the hatching day (day 0 ), the chicks were stimulated for $2 \times 15$ min with the imprinting tone without contact to a mother surrogate (hen decoy).

Experiment III: All chicks for this experiment were sacrificed on day 0 .

Naive chicks $(\mathrm{n}=4)$ : The chicks were reared in the isolation boxes without any sensory or social contact.

I-tone chicks, day $0(\mathrm{n}=4)$ : Chicks of this group were stimulated on the hatching day for $2 \times 15 \mathrm{~min}$ with the imprinting tone in the presence of a mother surrogate (hen decoy) and then sacrificed $80 \mathrm{~min}$ after the stimulation was terminated.

\section{Golgi-Cox staining and analysis}

The brains used for analysis were processed according to a Golgi-Cox method, modified by Glaser \& Van der Loos (1981), which enables both Golgi-Cox staining and Nissl staining in the same section. In $150 \mu \mathrm{m}$ sections, type I neurons of the MNH (according to Wallhäußer \& Scheich, 1987) were analyzed using an image analysis system Neurolucida $^{\mathrm{TM}}$ (MicroBright Field, Inc.), which allows a quantitative 3-D analysis of microscopic images.

Using this system, we analyzed dendritic trees in their complete extension in the three-dimensional space. We analyzed an overall of 29 brains: 21 from chicks on postnatal day 7 plus 8 from chicks on day 0 . In each group, more than 80 dendrites of $\mathrm{MNH}-$ neurons were analyzed. The mean spine frequencies (number of spines per $10 \mu \mathrm{m}$ ) were calculated and tested for significant differences between the groups using a two-tailed Mann-Whitney U-test.

\section{RESULTS}

\section{Experiment I}

The magnitude of spine elimination in the MNH of chicks on postnatal day 7 is correlated with the degree of experience that the chicks had acquired during the first days posthatch. The lowest spine frequency was found in the imprinted chicks with the greatest experience. Compared with naive control animals, the imprinted chicks displayed a $40.5 \%$ lower spine frequency on the 3 . and 4 . branch order of type I neurons (Fig. 3A). The imprinted chicks also showed lower spine frequencies than did either the I-tone chicks (17\%) or the I/A-chicks (11\%). The I-tone chicks, however, displayed a $28.5 \%$ lower spine frequency on the 3. and 4. branch order of type I neurons than did the age-matched, naive control animals (Fig. 3A). This finding indicates that the brief $30-\mathrm{min}$ experience with the imprinting situation (tone stimulus + mother surrogate) on the hatching day was sufficient to induce spine elimination in the $\mathrm{MNH}$. Further experiences in I/A-chicks and imprinted chicks led to a slight enhancement of this effect. The same effects were found on all dendritic segments from the basal (1.) to the distal (4.) branch orders, with exception of the first two segments, in which spine frequencies in the I/A-tone chicks and in the imprinted chicks were similar (Fig. 3B).

\section{Experiment II}

"Passive" acoustic stimulation without emotional reward did not lead to detectable changes of spine frequency in the MNH. On postnatal day 7, the spine - frequencies in chicks receiving "passive" acoustic stimulation on the hatching day were similar to those of age-matched, naive controls (Fig. 4). This effect was found on all dendritic segments from basal (1.) to distal (4.). This finding indicates that an association between a sensory (acoustic) stimulus and an emotional component is required for the induction of the synaptic rearrangements in the associative forebrain area MNH (compare with results from Experiment I).

\section{Experiment III}

Eighty min after termination of the 30-min exposure to the imprinting situation (tone stimulus + mother surrogate), no change of spine frequency was observed in the MNH. On day 0 , no difference in the average spine frequencies of type I neurons was measured between stimulated and age-matched naive control chicks (Fig. 5). 


\section{DISCUSSION}

Our results demonstrate that the very first 30 min experience with the imprinting situation (tone stimulus + mother surrogate) alone is sufficient to trigger the spine elimination found at postnatal day 7 on type I neurons in the associative forebrain area MNH. No change in spine density was detected shortly $(80 \mathrm{~min})$ after this first experience with the imprinting situation. The magnitude of the spine reduction was related to the degree of experience, as reflected by the lower spine frequencies in the chicks that had performed multiple behavioral tests.

Spines are considered specialized structures subserving a biochemical compartmentalization and providing a protected microenvironment for calcium and other messengers and, therefore, playing a key role in the expression of synaptic plasticity (Horner, 1993; Koch \& Zador, 1993; Harris \& Kater, 1994; Segal, 1995). Several studies have suggested that changes in the density and morphology of these specialized structures may be a principal cellular correlate of learning and memory processes. Evidence is accumulating that, in particular, the elimination of spine synapses may be characteristic for juvenile learning. The spine loss after filial imprinting in domestic chicks (Wallhäußer \& Scheich, 1987 and results in the present paper) is in principle in accordance with comparable results in the MNH of zebra finches, where social experience leads to a reduction of spine density (Rollenhagen \& Bischof, 1994). Song- or speech-learning, another juvenile learning process, induces a $41 \%$ decrease of spine density in the IMAN (lateral part of the magnocellular nucleus of the anterior neostriatum) of male zebra finches (Wallhäußer-Franke et al., 1995 ), and a $50 \%$ loss of dendritic spines was found in the forebrain vocal control system of mynah birds (Rausch \& Scheich, 1982). Without being interpretable in relation to experience or learning, a reduction of synaptic redundancy by elimination of supernumery spine synapses has been described in the mammalian brain, which seems to be a principle for the establishment and refinement of functional neuronal circuits. In human and non-human primate frontal cortical areas, an initial synaptic proliferation is followed by a substantial synaptic elimination during adolescence (Huttenlocher, 1979; Zecevic et al., 1989; Bourgeois \& Rakic, 1993; Wolff \& Missler, 1993).

In contrast to the described regressive synaptic changes after imprinting-like learning, other learning events appear to induce proliferative processes. Spatial learning in a complex environment has been shown to induce an increase of dendritic spines on basal dendrites of CA1 pyramidal cells in the hippocampus of rats (Moser et al., 1994). Similar results were obtained by comparing the spine densities of rats that had been reared in a complex or enriched environment with those of isolated control animals. Cortical and striatal neurons of rats who are exposed to an enriched environment display higher spine densities (Comery et al., 1995; Globus et al., 1973; Rosenzweig et al., 1973). Furthermore, increases of spine density on CA1 hippocampal cells were found in rats that had been handled and injected daily (Horner et al., 1991) and in dentate granule cells after the induction of longterm potentiation (LTP) (Trommald et al., 1996).

The results of the present study indicate that the extent of experience with the imprinting situation determines the degree of spine reduction. Furthermore, our studies have revealed that, unlike during the development of sensory systems, the sensory stimulus alone is not sufficient to induce synaptic reorganization. Thus, in higher associative brain areas, the association between the acoustic stimulus and an emotional stimulus appears to be essential for the induction of the synaptic selection process. This view is supported by results from electrophysiological studies, in which $\mathrm{MNH}$ neuronal units were shown to develop enhanced responsiveness toward the acoustic imprinting stimulus only when it is presented in the presence of a mother surrogate during the training session (Bredenkötter \& Braun, 1997).

The imprinting-induced reorganization of spine synapses requires several days, and no changes of spine density were detectable immediately ( $80 \mathrm{~min}$ ) after the first experience with the imprinting situation. Yet, this finding does not exclude the possibility that short-term changes may occur in other neuronal and synaptic subpopulations, similar to observations after an aversive learning task in young chicks (Doubell \& Stewart, 1993; Stewart \& Rusakov, 1995). 
Our results indicate that a certain amount of sensory and emotional experience is required for the induction of synaptic reorganization within associative forebrain areas and provide evidence that the observed spine reduction is correlated to a learning process, rather than representing an exclusively developmental process. Specific elimination of dendritic spines as a basic principle of information storage has been proposed in a synaptic-selection hypothesis of imprinting (Scheich, 1987; Wallhäußer \& Scheich, 1987; Scheich et al., 1991). According to this view, adequate environmental stimuli that are present during the sensitive phase of imprinting activate only a certain subset of inputs, eventually leading to a selective stabilization of these synaptic connections, whereas in parallel, mechanisms leading to a subsequent elimination of non-activated spine synapses are induced. Alternatively, the proliferation of spine synapses occurring in the isolated chicks during the first 7 postnatal days (Scheich et al., 1991) may be suppressed in imprinted animals. This notion, however, appears unlikely in view of control experiments demonstrating that chicks, which were imprinted on postnatal day 7 after the initial proliferative phase is terminated, display a similar pruning of spine synapses as chicks imprinted immediately after birth (Scheich et al., 1987).

What is the functional implication of this experience-regulated synaptic reorganization of higher associative brain regions? One proposal is that the initial overproduction of synapses serves to ensure that no target cell lacks contacts, and that during the subsequent activity-regulated competition, a reduction to the mature synaptic relationships takes place (Changeux \& Danchin, 1976; Lohof et al., 1996). This may lead to a more efficient neuronal network that responds more selectively to relevant environmental stimuli. This view is supported by results from metabolic, electrophysiological, and microdialysis studies, in which an enhanced neuronal responsiveness toward the learned acoustic imprinting stimulus was found in the MNH (Wallhäußer \& Scheich, 1987; Bock et al., 1996; Gruß \& Braun, 1996; Bredenkötter \& Braun, 1997).
The understanding of the mechanisms underlying emotionally regulated, experience-dependent modification of functional brain circuits during early childhood may be important in view of the idea that deviations in the normal postnatal maturation of the human cortex may underlie certain psychotic disorders (see Keshavan et al., 1994). For instance, schizophrenia may result from an abnormality in the specific synaptic elimination processes in areas of the brain that are critical for cognitive development (Feinberg, 1982). Feinberg suggested, “.... as a result of some abnormality in this process too many, too few, or the wrong synapses are eliminated". In line with this idea are the results from a recent study, in which reduced spine densities were reported in the frontal and temporal cortex of schizophrenic patients (Hirsch et al., 1997).

\section{ACKNOWLEDGEMENTS}

We wish to express our thanks to Ute Kreher and Petra Kremz for excellent technical assistance. This work was supported by DFG Br 1692.4-1 and a grant from the state of Saxony-Anhalt 6553/ 84273 .

\section{REFERENCES}

Bateson, PPG. The characteristics and context of imprinting. Biol Rev 1966; 41: 177-220.

Bock J, Schnabel R, Braun K. Role of the dorso-caudal neostriatum in filial imprinting of the domestic chick: a pharmacological and autoradiographical approach focused on the involvement of NMDA-receptors. Europ J Neurosci 1997; 9: 1262-1272.

Bock J, Wolf A, Braun K. Influence of the N-methyl-Daspartate receptor antagonist DL-2-amino-5-phosphono valeric acid on auditory filial imprinting in the domestic chick. Neurobiol Learn Mem 1996; 65: 177188.

Bourgeois JP, Rakic P. Changes of synaptic density in the primary visual cortex of the macaque monkey from fetal to adult stage. J Neurosci. 1993; 13: 2801-2820.

Bredenkötter M, Braun K. Enhanced auditory evoked neuronal activity in the mediorostral neostriatum/ hyperstriatum after auditory filial imprinting in the domestic chick. Neurosci 1997; 2: 355-365. 
Changeux J-P, Danchin A. Selective stabilization of developing synapses as a mechanism for the specification of neuronal networks. Nature 1976; 264: 705-712.

Comery TA, Shah R, Greenough WT. Differential rearing alters spine density on medium-sized spiny neurons in the rat corpus striatum: evidence for association of morphological plasticity with early response gene expression. Neurobiol Learn Mem 1995; 63: 217-219.

Doubell TP, Stewart MG. Short-term changes in the numerical density of synapses in the intermediate and medial hyperstriatum ventrale following one-trial passive avoidance training in the chick. $J$ Neurosci 1993; 13: 2230-2236.

Feinberg I. Schizophrenia: caused by a fault in programmed synaptic elimination during adolescence? J Psychiatr Res 1982; 17: 319-330.

Glaser EM, Van der Loos H Analysis of thick brain sections by obverse-reverse computer microscopy: application of a new, high clarity Golgi-Nissl stain. J Neurosci Meth 1981; 4: 117-125.

Globus A, Rosenzweig MR, Bennett EL, Diamond M. Effects of differential experience on dendritic spine counts in rat cerebral cortex. J Comp Physiol Psychol 1973; 82: 175-181.

Goodman CS, Shatz CJ Developmental mechanisms that generate precise patterns of neuronal connectivity. Neuron 1993; 10 (Suppl): 77-98.

Gruß M, Braun K. Stimulus-evoked increase of glutamate in the mediorostral neostriatum/hyperstriatum ventrale of domestic chick after auditory filial imprinting: an in vivo micordialysis study. J Neurochem 1996; 66: 1167-1173.

Gruß M, Braun K. Distinct activation of monoaminergic pathways in chick brain in relation to auditory imprinting and stressful situations: a microdialysis study. Neurosci 1997; 76: 891-899.

Harlow HF, Harlow MK. Social deprivation in monkeys. Scientific American 1962; 207: 137-146.

Harris KM, Kater SB. Dendritic spines: cellular specializations imparting both stability and flexibility to synaptic function. Ann Rev Neurosci 1994; 17: 341-371.

Hess E. Imprinting. New York: Van Nostrand, 1973.

Hirsch SR, Das I, Garey LJ, deBelleroche J. A pivotal role for glutamate in the pathogenesis of schizophrenia and its cognitive dysfunction. Pharmacol Biochem Behav 1997; 56; 797-802.

Horner $\mathrm{CH}$. Plasticity of the dendritic spine. Progr Neurobiol 1993; 41: 281-321.

Horner CH, O'Regan M, Arbuthnott E. Neural plasticity of the hippocampal (CA1) pyramidal cell-quantitative changes in spine density following handling and injection for drug testing. J Anat 1991; 174: 229-238.
Huttenlocher PR. Synaptic density in human frontal cortex: developmental changes and effects of aging. Brain Res 1979; 163: 195-205.

Keshavan MS, Anderson S, Pettegrew JW. Is schizophrenia due to excessive synaptic pruning in the prefrontal cortex? The Feinberg hypothesis revisited. J Psychiat Res 1994; 28: 239-265.

Koch C, Zador A. The function of dendritic spines: devices subserving biochemical rather than electrical compartmentalization. J Neurosci 1993; 13: 413-422.

Lohof AM, Delhaye-Bouchaud N, Mariani, J Synapse elimination in the central nervous system: functional significance and cellular mechanisms. Rev Neurosci 1996; 7: 85-101.

Lorenz K. Der Kumpan in der Umwelt des Vogels. J Ornithol 1935; 83: 137-213 and 289-413.

Maier V, Scheich H. Acoustic imprinting leads to differential 2-deoxyglucose uptake in the chick forebrain. Proc Natl Acad Sci USA 1983; 80: 3860-3864.

Metzger M, Jiang S, Braun K. Organization of the dorsocaudal neostriatal complex: A retrograde and anterograde tracing study in the domestic chick with special emphasis on pathways relevant to imprinting. J Comp Neurol 1998; 395: 380-404.

Metzger M, Jiang S, Wang J, Braun K. Organization of the dopaminergic innervation of forebrain areas relevant to learning: A combined immunohistochemical/retrograde tracing study in the domestic chick. J Comp Neurol 1996; 376: 1-27.

Moser M-B, Trommald M, Andersen P. An increase in dendritic spine density on hippocampal CA1 pyramidal cells following spatial learning in adult rats suggests the formation of new synapses. Proc Natl Acad Sci USA 1994; 91: 12673-12675.

Rausch G, Scheich H. Dendritic spine loss and enlargement during maturation of the speech control system in the mynah bird (Gracula religiosa). Neurosci Lett 1982; 29: 129-133.

Rollenhagen A, Bischof HJ Phase specific morphological changes induced by social experience in two forebrain areas of the zebra finch. Behav. Brain Res. 1994; 65: 83-88.

Rosenzweig MR, Bennett EL, Diamond MC. Effects of differential experience in dendritic spine counts in rat cerebellar cortex. J Comp Physiol Psychol 1973; 82: 175-181.

Scheich H. Neural correlates of auditory filial imprinting. J Comp Physiol A 1987; 161: 605-619.

Scheich H, Wallhäußer-Franke E, Braun K. Does synaptic selection explain auditory imprinting? In: Squire LR, Weinberger NM, Lynch G, McGaugh J, eds, Memory: Organisation and locus of change. Oxford: Oxford Uni-versity Press 1991; 114-159.

Segal M. Dendritic spines for neuroprotection: a hypo- 
thesis. TINS 1995; 18: 468-471.

Skeels HM. Adult status of children with contrasting early life experiences: a follow-up study. Monographs of the Society for Research in Child Development 1966; 31: $1-65$.

Spitz RA. Hospitalism. Psychoanalytic Study of the Child; 1: 53-74.

Stewart MG, Rusakov DA. Morphological changes associated with stages of memory formation in the chick following passive avoidance training. Behav Brain Res 1995; 66: 21-28.

Trommald M, Hulleberg G, Andersen P. Long-term potentiation is associated with new excitatory spine synapses on rat dentate granule cells. Learn Mem 1996; 3: 218-228.

Wallhäußer E, Scheich H. Auditory imprinting leads to differential 2-deoxyglucose uptake and dendritic spine loss in the chick rostral forebrain. Dev Brain Res 1987; 31: 29-44.

Wallhäußer-Franke E, Nixdorf-Bergweiler BE, DeVoogd TJ. Song isolation is associated with maintaining high spine frequencies on zebra finch IMAN neurons. Neurobiol Learn Mem 1995; 64: 25-35.

Wolff JR, Missler M. Synaptic remodeling and elimination as integral processes of synaptogenesis. APMIS (Suppl) 1993; 40: 9-23.

Zecevic N, Bourgeois JP, Rakic P. Changes in synaptic density in motor cortex of rhesus monkey during fetal and postnatal life. Dev Brain Res 1989; 50: 11-31.

Westerink BHC, Damsma G, Rollema H, de Vries JB, Horn AS. Scope and limitations of in vivo brain dialysis: a comparison of its application to various neuro-transmitter systems. Life Sci 1987; 41: 17631776. 

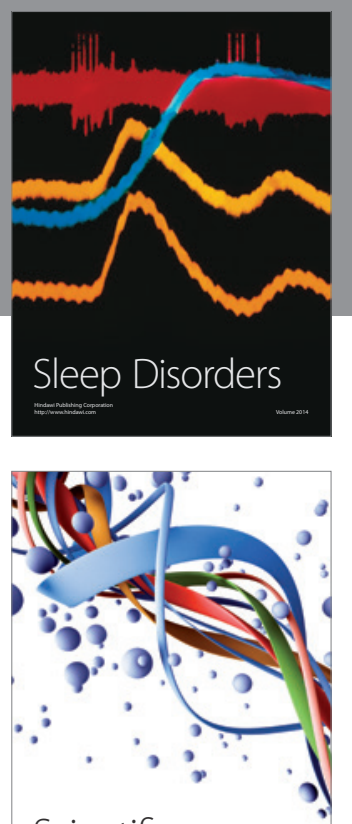

Scientifica
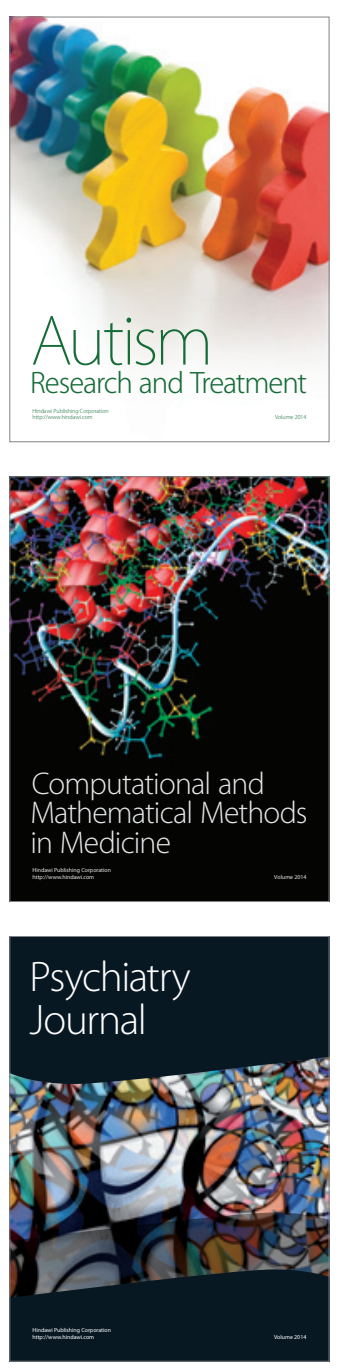
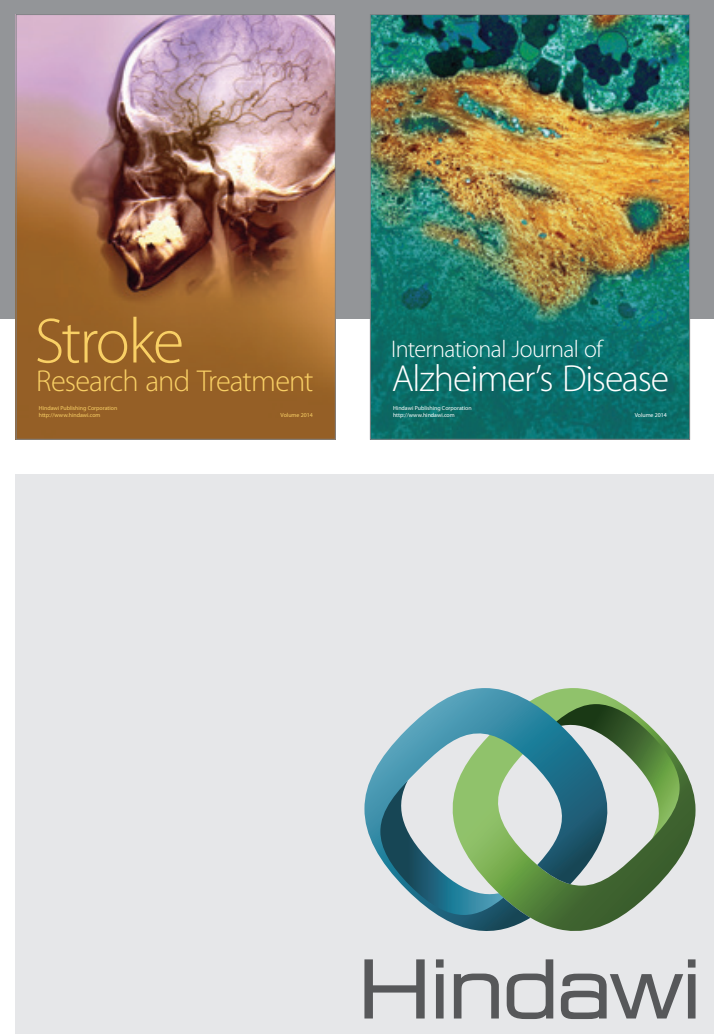

Submit your manuscripts at

http://www.hindawi.com
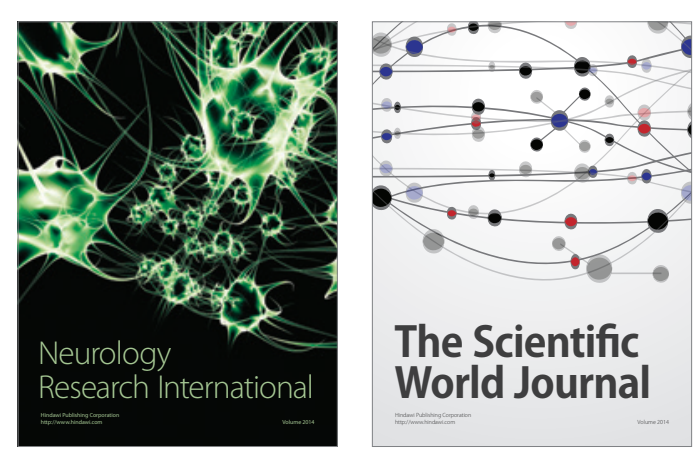

The Scientific World Journal

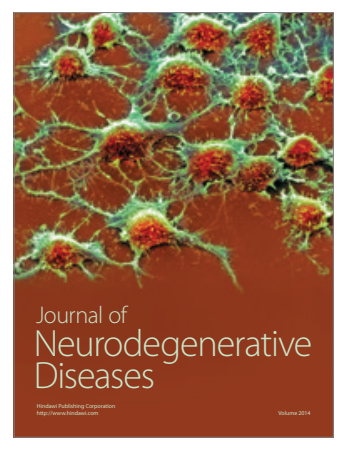

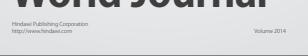

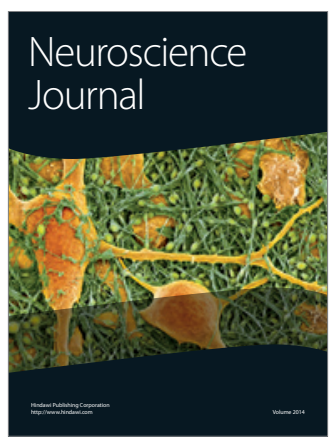

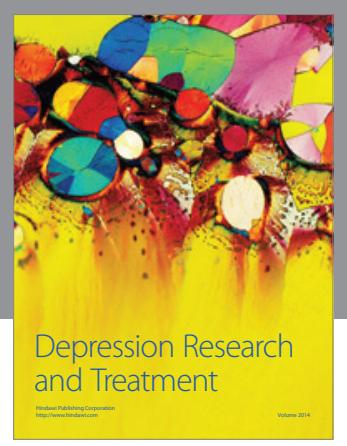
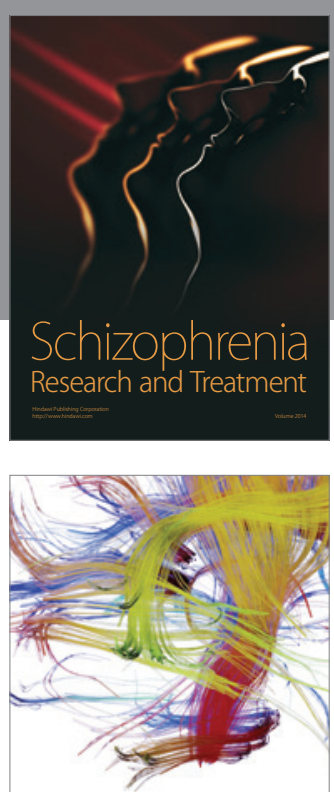

Brain Science

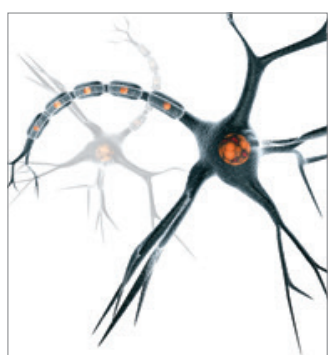

Neural Plasticity
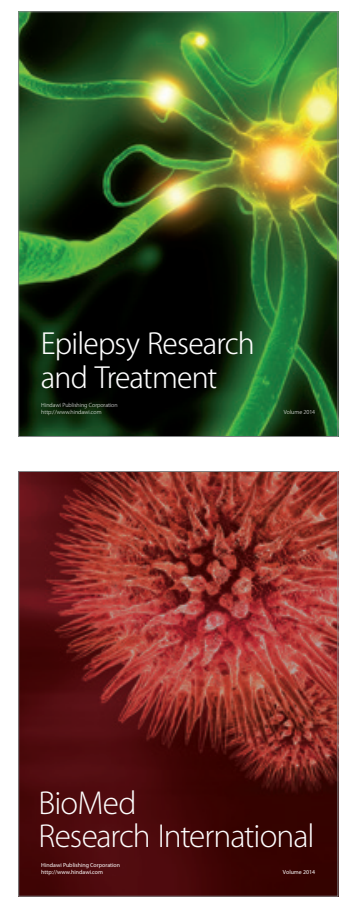

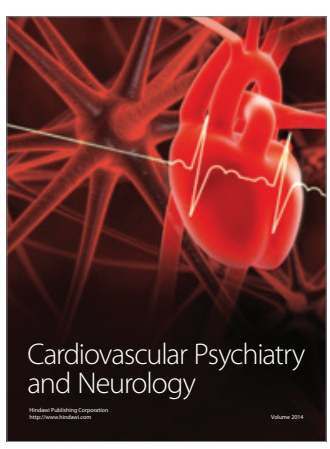

Parkinson's

Disease
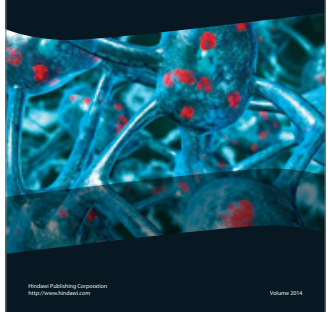